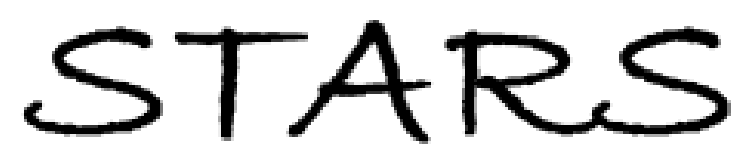

University of Central Florida

STARS

2013

\title{
A Randomized Trial Of Attention Training For Generalized Social Phobia: Does Attention Training Change Social Behavior?
}

Brian Bunnell

University of Central Florida

Part of the Clinical Psychology Commons

Find similar works at: https://stars.library.ucf.edu/etd

University of Central Florida Libraries http://library.ucf.edu

This Masters Thesis (Open Access) is brought to you for free and open access by STARS. It has been accepted for inclusion in Electronic Theses and Dissertations, 2004-2019 by an authorized administrator of STARS. For more information, please contact STARS@ucf.edu.

\section{STARS Citation}

Bunnell, Brian, "A Randomized Trial Of Attention Training For Generalized Social Phobia: Does Attention Training Change Social Behavior?" (2013). Electronic Theses and Dissertations, 2004-2019. 2516. https://stars.library.ucf.edu/etd/2516

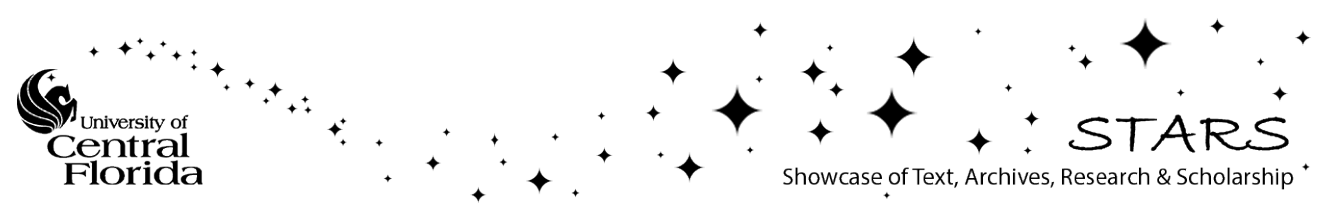




\section{A RANDOMIZED TRIAL OF ATTENTION TRAINING FOR GENERALIZED SOCIAL PHOBIA: DOES ATTENTION TRAINING CHANGE SOCIAL BEHAVIOR?}

by

BRIAN E. BUNNELL

B.A. Arizona State University, 2010

A thesis submitted in partial fulfillment of the requirements

for the degree of Master of Science

in the Department of Psychology

in the College of Sciences

at the University of Central Florida

Orlando, Florida

Spring Term

2013

Major Professor: Deborah C. Beidel 
(C) 2013 Brian E. Bunnell 


\begin{abstract}
The use of attention training protocols for the treatment of generalized social anxiety disorder (SAD) is undergoing increased examination. Initial investigations were positive but more recent investigations have been less supportive of the treatment paradigm. One significant limitation of current investigations may be over-reliance on self-report. In this investigation, we expanded on initial investigations by using a multimodal assessment of patient functioning (i.e., including behavioral assessment). Patients with a primary diagnosis of SAD $(n=31)$ were randomly assigned to eight sessions of attention training $(n=15)$ or placebo/control $(n=16)$. Participants were assessed at pre- and post-treatment via self- and clinician-report of social anxiety as well as anxious and behavioral response to two in vivo social interactions. Results revealed no differences between groups at post-treatment for all study outcome variables, suggesting a lack of effect for the attention training condition. The results are concordant with recent investigations finding a lack of support for the use of attention training as an efficacious treatment for patients with SAD.
\end{abstract}




\section{ACKNOWLEDGMENTS}

The author wishes to acknowledge and thank Dr. Deborah Beidel for her close mentorship, inspiring passion, valuable time, and supportive friendship over the past few years. Her example and guidance has led to a great start to an academic career in meaningful clinical psychological research.

The author also wishes to express his gratitude to his thesis committee as well as the researchers at the University of Central Florida Anxiety Disorders Clinic for their help and support throughout the course of this study.

The author would also like to thank his family who taught him the value of hard work and perseverance. Last but not least, the author would like to thank his wife Avianne for her love, support and understanding, which motivates him to reach for success in all of his endeavors. 


\section{TABLE OF CONTENTS}

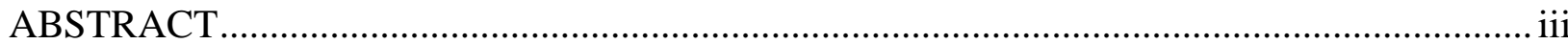

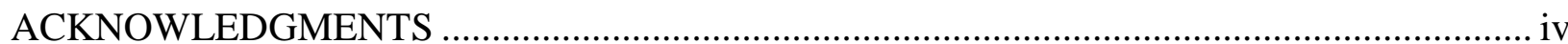

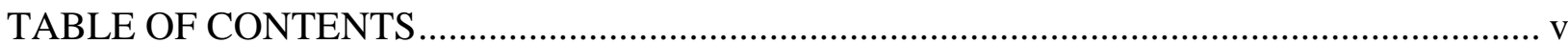

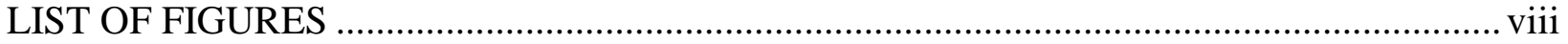

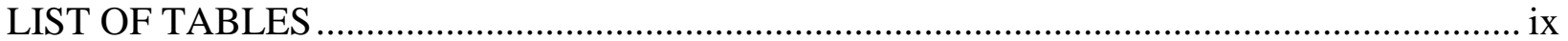

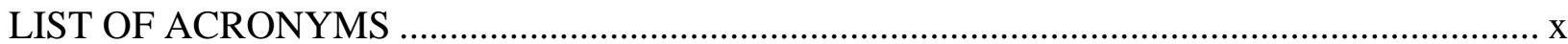

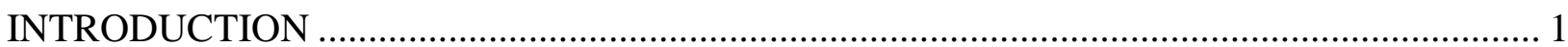

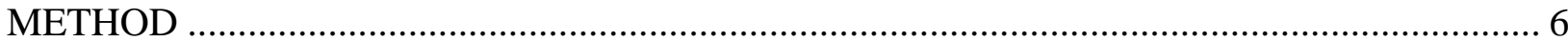

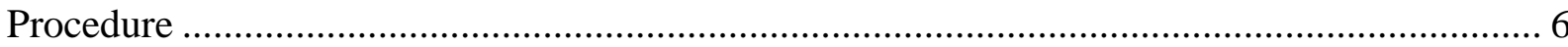

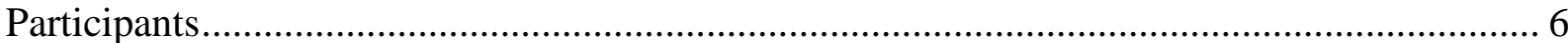

Assessment

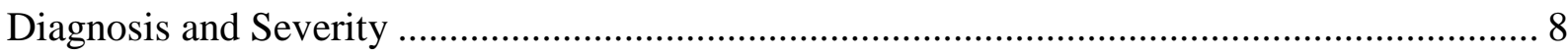

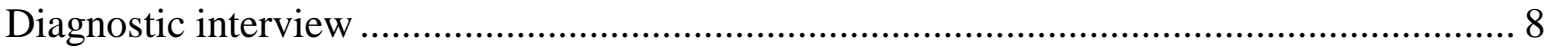

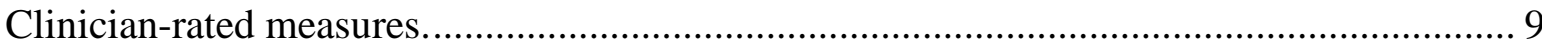

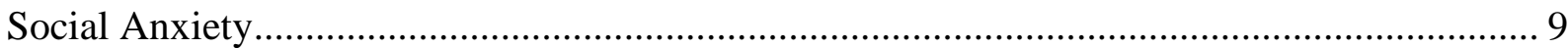

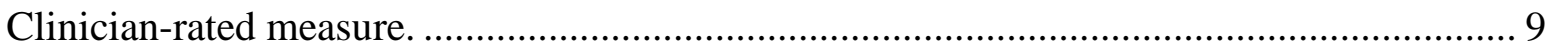

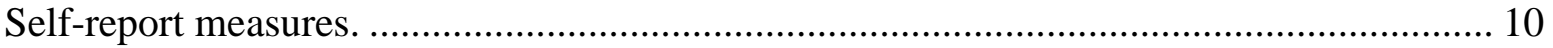

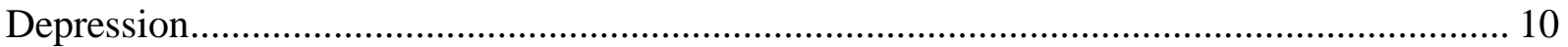

Behavioral Assessment of Social Anxiety and Behavior .................................................. 11 
UCT.

IST.

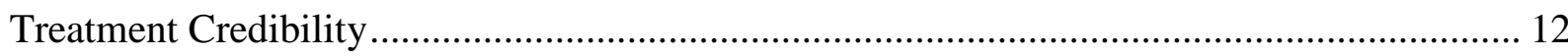



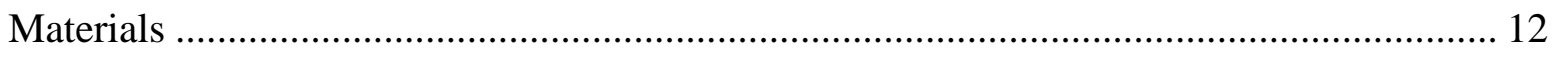

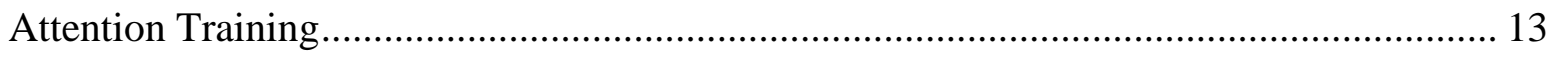

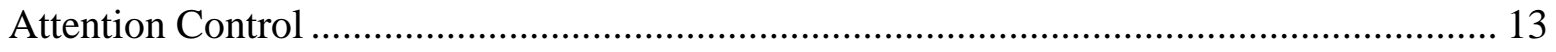

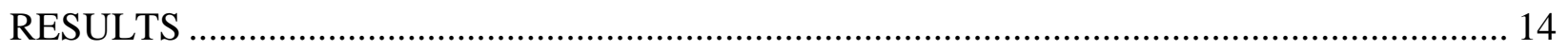

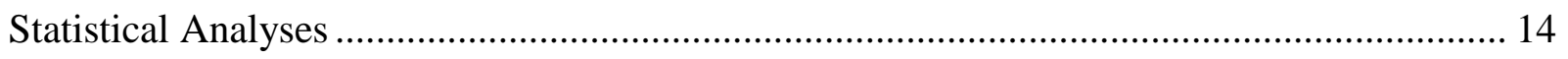

Diagnosis and Severity at Post-Treatment................................................................... 15

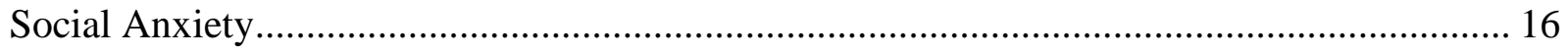

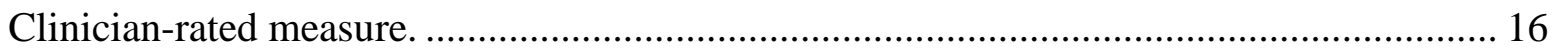

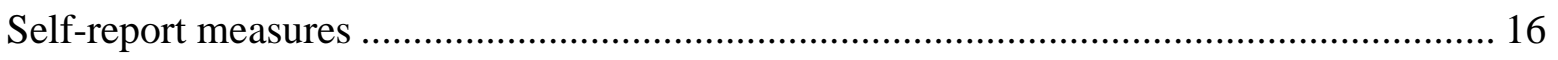

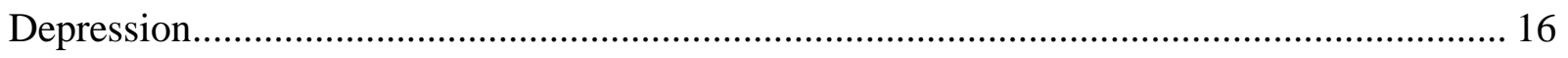

Behavioral Assessment of Anxiety and Social Behavior ................................................ 16

Anxiety level during social interactions ............................................................... 16

Social behaviors during social interactions............................................................ 16

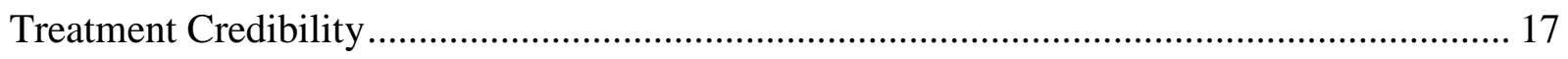

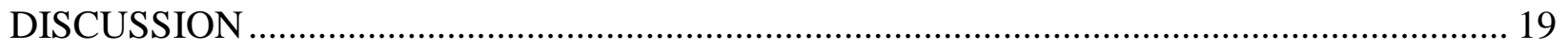

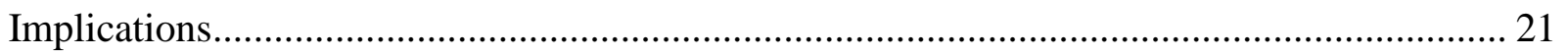


Limitations .

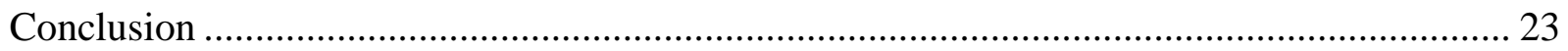

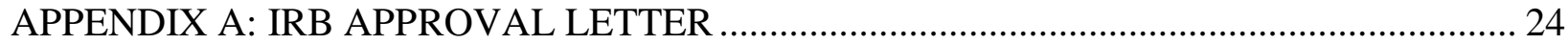

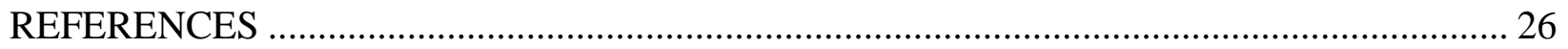




\section{LIST OF FIGURES}

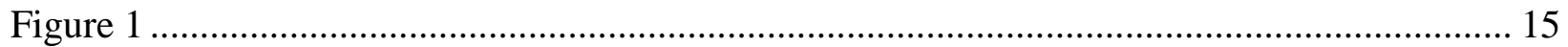

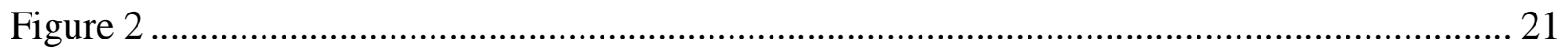




\section{LIST OF TABLES}

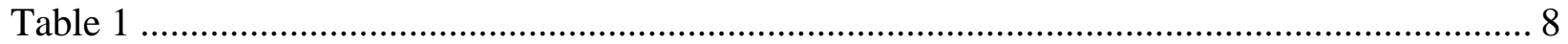

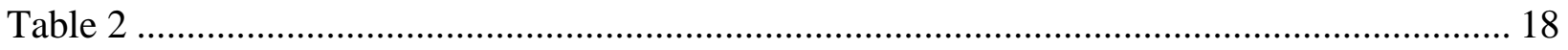




\section{LIST OF ACRONYMS}

AC Attention Control

ADIS Anxiety Disorders Interview Schedule

ANCOVA Analysis of covariance

ANOVA Analysis of variance

APA American Psychiatric Association

AT Attention Training

BARS Behavioral Avoidance Rating Scale

BDI-II Beck Depression Inventory-II

BSPS Brief Social Phobia Scale

CGI Clinical Global Impressions

DSM-IV-TR Diagnostic and Statistical Manual of Mental Disorders (4 ${ }^{\text {th }}$ ed.) Text Revision

IST Impromptu Speech Task

LSAS-SR Liebowitz Social Anxiety Scale-Self Report

SAD Social Anxiety Disorder

SPAI Social Phobia and Anxiety Inventory

UCT Unstructured Conversation Task 


\section{INTRODUCTION}

Individuals presenting with social anxiety disorder (SAD; also termed social phobia) experience an intense fear and apprehension of social situations during which they might be evaluated by others (DSM-IV-TR; American Psychiatric Association [APA], 2000). In addition to the distress associated with these social situations, SAD is frequently marked by avoidance of the anxiety-provoking situation (e.g., avoiding conversations and/or giving presentations in a class or at work). The physiological and psychological distress, anticipatory response, and behavioral avoidance associated with SAD create significant functional impairment. Two subtypes have been identified for people with SAD. These include the nongeneralized or specific (social fears are limited to few, specific social situations) and the generalized (social fears are present in most social situations) subtypes (APA, 2000).

$\mathrm{SAD}$ is a common disorder, with prevalence rates ranging from $1-15 \%$ of the general population (APA, 2000; Costello, Eggar, \& Angold, 2004; Costello, Eggar, \& Angold, 2005; Heimberg, Stein, Hiripi, \& Kessler, 2000) and the typical age of onset is early to midadolescence (age 11 to 15; DeWit, Ogborne, Offord \& MacDonald, 1999; Silverman et al., 1999; Weiss \& Last, 2001). Earlier onset SAD is associated with more negative outcomes including comorbid anxiety disorders, depression, substance use, and conduct problems later in life (Beidel \& Turner, 1998; Grant et al., 2005; Kessler, 2003; Lecrubier, 1998).

Of particular importance, relative to impairment, is that an early history of SAD may also result in dysfunctional social skills (Beidel, Rao, Scharfstein, Wong, \& Alfano, 2010; Turner, Beidel, Dancu, \& Stanley, 1989). As children and adolescents with SAD progressively avoid social situations, they miss opportunities to develop the social skills necessary for effective social interaction. The pattern of inadequate skill and social distress associated with SAD, in turn, may 
result in additional negative effects (e.g., co-morbid anxiety disorders, depression, substance abuse, and behavioral problems), and create significantly more dysfunction (e.g., dropping out of school, turning down job offers, interpersonal relationship problems) with age (Clark, 1993; Costello et al., 2003; Lecrubier, 1998; Rao et al., 2007; Stein, Torgrud, \& Walker, 2000).

In addition to its behavioral elements, cognitive aspects of SAD have received increased attention. According to cognitive theories, anxious individuals direct their attention toward threatening stimuli pertinent to their specific concerns (e.g., Beck, Emery, \& Greenberg, 1985; Eysenck, 1997; Mogg \& Bradley, 1998; Rapee \& Heimberg, 1997; Williams, Watts, MacLeod, \& Mathews, 1997). This attentional bias is theorized to be influential in the etiological and maintenance aspects of anxiety disorders, particularly SAD, and has therefore translated into research examining attentional biases toward symptom-specific stimuli associated with SAD.

There has been increasing interest in the role of attentional bias theory in SAD (e.g., Asmundson \& Stein, 1994; Becker, Rinck, Margraf, \& Roth, 2001; Bradley, Mogg, \& Millar, 1999). Yet some research suggests that socially anxious individuals ultimately avoid, rather than selectively attend to, external socially threatening stimuli (Chen, Ehlers, Clark \& Mansell, 2002; Clark \& Wells, 1995; Gamble \& Rapee, 2010; Garner, Mogg, \& Bradley, 2006; Mansell, Clark, Ehlers, \& Chen, 1999). Furthermore, other studies suggest there is little or no relationship and results have varied depending on contextual factors (Bradley et al., 1997; Mansell, Ehlers, Clark, \& Chen, 2002; Pineles \& Mineka, 2005).

Support for the existence of attentional biases in socially anxious participants has been found using a variety of measurement methods. Examples of these include heightened activation of the anterior cingulate cortex while viewing socially evaluative faces (Amir et al., 2005), elevated duration of eye-gaze toward faces with emotional valence as measured by infrared eye 
tracking systems (Bradley, Mogg, \& Millar, 1999), and biased responding toward socially threatening/related words during modified Stroop (1935) Color-Naming Tasks (Becker, Rinck, Margraf, \& Roth, 2001; Holle, Neely, \& Heimberg, 1997; Hope, Rapee, Heimberg, \& Dombeck, 1990; Maidenberg, Chen, Craske, Bohn, \& Bystritsky, 1996; Mattia, Heimberg, \& Hope, 1993; McNeil et al., 1995; Spector, Pecknold, \& Libman, 2003). Computerized dot-probe paradigms (MacLeod, Mathews, \& Tata, 1986) have also been used to measure attentional biases in this population. Briefly, this paradigm includes the short presentation (typically 500ms) of two stimuli (e.g., neutral/threatening words or pictures). Upon the disappearance of the stimuli, a dot (also referred to as a probe) appears in the place of one of the stimuli. Conceptually, a participant is biased toward attending to a particular stimulus type (e.g., a picture of a socially-threatening face) if he or she recognizes the presence of the dot with increased speed and accuracy when it takes the place of that particular stimulus type. Based on the use of this paradigm, attentional biases in socially anxious samples have been observed toward socially-threatening words (Amir, Elias, Klumpp, \& Przeworski, 2003; Asmundson \& Stein, 1994; Ononaiye, Turpin, \& Reidy, 2007) and later pictures of socially-threatening faces (Mogg \& Bradley, 2002; Mogg, Philippot, \& Bradley, 2004; Pishyar, Harris, \& Menzies, 2004; Sposari \& Rapee, 2007), as single words are unlikely to be the source of threat while participants with SAD engage in social situations (Bradley et al., 1997).

Researchers also have examined the manipulability of attentional biases. For example, some investigations have observed decreases in the severity of attentional biases following cognitive behavioral therapy (Calamaras, Tone, \& Anderson, 2012; Mattia et al., 1993; Pishyar, Harris, \& Menzies, 2008; Price, Tone, \& Anderson, 2011). The potential malleability of attentional biases prompted the designing of specific attention training paradigms for participants 
with social anxiety. Studies examining the utility of attention training (also attention bias modification) treatments in people with SAD are emerging. Two initial randomized control trials (RCTs) used an identical eight-session attention training protocol (i.e., Amir et al., 2009 and Schmidt, Richey, Buckner, \& Timpano, 2009), and both concluded that treatment gains were observed in the treatment condition above and beyond that of a placebo control. However, in one trial, significant between-group differences were not observed at post-treatment for clinician- and self-report measures (Schmidt et al., 2009).

Infrequently discussed, but nonetheless important caveats also exist regarding the extent of clinically significant change observed in these investigations. Specifically, although statistical differences in self- and clinician-reported social anxiety were observed between the treatment conditions, at post-treatment average scores on these measures still fell far above the scores delineating the clinical range for $\mathrm{SAD}$, as recommended by prior literature. For example, average post-treatment scores on the Social Phobia and Anxiety Inventory (SPAI; Turner, Beidel, \& Dancu, 1996) were 99.1 (Amir et al., 2009) and 92.47 (Schmidt et al., 2009), exceeding established cut-off scores of 60 for probable SAD. Despite self-reported social anxiety, large percentages of treated participants no longer met diagnostic criteria for SAD (50\% and 72\% for Amir et al. (2009) and Schmidt et al. (2009), respectively). Moreover, neither investigation attempted to examine changes in participants' social behavior during social interactions, previously identified as a common deficit in patients with SAD and a considerable feature of the disorder (Beidel et al., 2010; Turner et al., 1989). Since the time of the initial publication, subsequent RCTs have failed to replicate the initial positive outcome (Boettcher, Berger, \& Renneberg, 2011; Carlbring et al., 2012; Heeren, Reese, McNally, \& Philippot, 2012; Neubauer et al., 2012) whether delivered in person or over the internet. 
To date, no study has replicated carefully the methodology of the initial investigations (Amir et al., 2009; Schmidt et al., 2009) while conducting a multimodal assessment of patient functioning (e.g., including behavioral assessment of patient functioning in addition to reports of social anxiety). Expanding the assessment strategy will allow examination of changes in social behavior and provide further elucidation of the clinically significant utility of this treatment. The specific hypotheses are as follows: 1 ) at post-treatment the percent of participants meeting diagnostic criteria for SAD in the treatment condition will be significantly lower than the percent meeting criteria in the placebo condition, 2) at post-treatment the mean SPAI score for the treatment condition will be significantly lower than that of the control condition, and 3) at posttreatment participants in the treatment condition will show significant improvement in social behavior during in-vivo social interactions, as reflected by increases in duration of eye-contact and time speaking as well as decreases in self-reported anxiety, relative to the control condition. 


\section{METHOD}

\section{Procedure}

Following informed consent, participants were assessed via a clinician administered diagnostic interview, self- and clinician-report measures, and a behavioral assessment of social skills at our Anxiety Disorders Clinic in the Southeastern United States. As in previous investigations, participants were informed that they would be randomly assigned to one of two groups: one group would receive the anxiety treatment and the other group would participate in the non-treatment condition. Participants were informed that the purpose of the study would be to evaluate the usefulness of new computer-based treatments for anxiety. They were then randomly assigned to either the Attention Training (AT; $n=15)$ or Attention Control (AC; $n=$ 16) condition using a Microsoft Excel random number generator formula. Participants completed a total of eight, bi-weekly treatment sessions during which they were instructed to attempt to identify the letter probe ( $E$ or $F$ ) as rapidly as possible without sacrificing accuracy. Following the completion of eight sessions, participants completed the post-treatment assessment, which was identical to the pre-treatment assessment. All assessments and treatment sessions were administered by senior doctoral students in clinical psychology (the first and third authors). Both the clinicians and participants were blinded to treatment condition until the conclusion of the study.

\section{Participants}

Participants were recruited via community advertisements targeting “shy adults”. Participants completed a telephone screen, followed by an in-person diagnostic interview, selfand clinician-report measures, and a behavioral assessment. Participants who met DSM-IV-TR criteria for a primary diagnosis of generalized SAD were invited to participate in the study. 
Exclusionary criteria (from Amir et al., 2009 and Schmidt et al., 2009) included (a) evidence of severe depression or suicidal intent, (b) evidence of current substance abuse or dependence, (c) evidence of current or past schizophrenia, bipolar disorder, or organic mental disorder, (d) any concurrent psychotherapy, (e) change in pharmacological treatments during the 12 weeks prior to study entry, and (f) cognitive-behavioral therapy within the previous 6 months.

A total of 31 adults participated in the study. Participants in the AT condition ranged from 18 to 45 years of age $(M=24.20, S D=7.99)$ and those in the AC condition ranged from 18 to 44 years of age $(M=24.44, S D=6.96)$. The two groups did not differ significantly in age, $F(1,29)=.008, p=.930, \eta_{\mathrm{p}}^{2}=.000$. There were slightly more males (62.5\%) than females (37.5\%) in the AC condition, whereas the opposite was true in the AT condition (46.7\% and $53.3 \%$, respectively) but the difference was not statistically significant, $\chi^{2}(1,31)=.784, p=.376$, $\Phi=.159$. Similarly, there were no group differences in race/ethnicity, $\chi^{2}(4,31)=2.372, p=.668$, $\Phi=.277$. The AT condition was comprised mostly of Caucasians (53.3\%), but also included Hispanic/Latino (26.7\%), Asian/Asian Indian (13.3\%), and African American (6.7\%) participants. Caucasians (56.2\%) made up the majority of the AC condition, which also included Asian/Asian Indian (18.8\%), Hispanic/Latino (18.8\%), and Biracial (6.3\%) participants. There were co-morbid diagnoses within both conditions. Specifically, 33.3\% of the AT condition and $18.8 \%$ of the AC condition met criteria for a secondary diagnosis, although this difference was not statistically significant, $\chi^{2}(6,31)=8.368, p=.212, \Phi=.520$. Co-morbid diagnoses in the AT condition included major depressive disorder (in partial remission; 6.7\%), dysthymic disorder (6.7\%), panic disorder without agoraphobia (6.7\%), and specific phobia (13.3\%). Co-morbid diagnoses in the AC condition included major depressive disorder (in either partial or full remission; 18.8\%). See Table 1 for participant demographics. 
Table 1

Demographics

\begin{tabular}{|c|c|c|}
\hline & $\begin{array}{c}\text { AT } \\
(n=15)\end{array}$ & $\begin{array}{c}\text { AC } \\
(n=16)\end{array}$ \\
\hline & $\mathrm{M}(S D)$ & $\mathrm{M}(S D)$ \\
\hline \multirow[t]{2}{*}{ Age } & $24.20(7.99)$ & $24.44(6.96)$ \\
\hline & $n(\%)$ & $n(\%)$ \\
\hline \multicolumn{3}{|l|}{ Sex } \\
\hline Male & $7(46.7)$ & $10(62.5)$ \\
\hline Female & $8(53.36)$ & $6(37.5)$ \\
\hline \multicolumn{3}{|l|}{ Race } \\
\hline African American & $1(6.7)$ & $0(0.0)$ \\
\hline Asian/Asian Indian & $2(13.3)$ & $3(18.8)$ \\
\hline Caucasian & $8(53.3)$ & $9(56.2)$ \\
\hline Latino/a & $4(26.7)$ & $3(18.8)$ \\
\hline Biracial & $0(0.0)$ & $1(6.2)$ \\
\hline \multicolumn{3}{|l|}{ Comorbid Diagnoses } \\
\hline Major Depressive Disorder & $1(6.7)$ & $3(18.8)$ \\
\hline Dysthymia & $1(6.7)$ & $0(0.0)$ \\
\hline Specific Phobia & $2(13.3)$ & $0(0.0)$ \\
\hline Panic Disorder without Agoraphobia & $1(6.7)$ & $0(0.0)$ \\
\hline
\end{tabular}

Note. All patients with major depressive disorder were in either partial or full remission.

\section{Assessment}

\section{Diagnosis and Severity}

Diagnostic interview. The Anxiety Disorders Interview Schedule (ADIS; Brown, Dinardo, \& Barlow, 1994) was used to assess for DSM-IV-TR Axis-I diagnoses. The ADIS was administered by trained doctoral student clinicians who demonstrated both aptitude and interrater reliability in performance prior to the start of the study. Training to proficiency followed similar methods used by Schmidt and colleagues (2009; reviewing ADIS training tapes, observing taped ADIS administration, observing live ADIS administration, and conducting ADIS interviews with a trained interviewer) to facilitate an accurate replication. Diagnoses were determined during weekly clinical meetings under the direction of a licensed clinical psychologist (the second author). Twenty percent of all diagnostic interviews conducted during the study were audiorecorded and rated by a blinded clinician to establish inter-rater reliability, which was excellent 
$(\kappa=1.0)$.

Clinician-rated measures. The Clinical Global Impressions (CGI; Guy, 1976) Severity of Illness and Improvement Scales are rated on an 8-point Likert-type rating scale (rated 0 to 7; not at all ill/very much improved to among the most extremely ill patients/very much worse). The CGI-Severity scale reflects the severity of the patient's condition and the CGI-Improvement scale reflects the degree to which the patient improved from pre- to post- treatment, based on the perception of the clinician. Participants with scores of either two or one (much improved or very much improved respectively) on the CGI-Improvement at post-treatment were classified as treatment responders.

The Behavioral Avoidance Rating Scale (BARS; Beidel et al., 2007) is a 7-point Likerttype scale (rated 0 to 6; no avoidance to complete avoidance) developed by the second author and reflects the degree to which the patient avoids social situations. Twenty percent of all clinician-rated measures were rated by a blinded clinician to establish inter-rater reliability, which was adequate for the CGI severity (ICC $=.91$ ), CGI-Improvement (ICC $=1.00)$, and BARS (ICC $=.79)$.

\section{Social Anxiety}

Clinician-rated measure. The Brief Social Phobia Scale (BSPS; Davidson et al., 1991) is an 11-item clinician-administered measure comprised of seven social situations and four physiological symptoms (i.e., blushing, palpitations, trembling, sweating) commonly experienced by individuals with SAD. Clinicians rate the patient's fear and avoidance relative to the social situations along with the severity of their physiological symptoms using a 5-point Likert-type rating scale (rated 0 to 4; none to extreme). Inter-rater reliability was adequate for the BSPS (ICC $=.88)$. 
Self-report measures. The Social Phobia and Anxiety Inventory (SPAI; Turner et al., 1989; Turner, Beidel, \& Dancu, 1996) is an empirically derived self-report measure that includes 45 items rated on a 7-point Likert-type scale (rated 0 to 6; never to always) reflecting the frequency of the rater's experiences. The SPAI provides both a Social Phobia and Agoraphobia subscale, and a difference score of the two which indicates a more pure measure of SAD, and which was used as the primary outcome measure of the current investigation. The SPAI has demonstrated good psychometric properties (Beidel, Turner, et al., 1989; Bunnell, Joseph, \& Beidel, 2012; Turner, Beidel, et al., 1989). The internal consistency was adequate for the SPAI (Cronbach's $\alpha=.97)$ in the current sample.

The Liebowitz Social Anxiety Scale-Self Report (LSAS-SR; Liebowitz, 1987) is a 24item self-report measure that assesses both fear (rated 0 to 3; none to severe) and avoidance (rated 0 to 3; never to usually) of social interaction and performance situations. The LSAS-SR has demonstrated good psychometric properties (Baker, Heinrichs, Kim, \& Hofmann, 2002; Fresco et al., 2001) and scores are comparable to those of the clinician-rated version (Fresco et al., 2001). The internal consistency was adequate for the LSAS-SR (Cronbach's $\alpha=.89$ ) in the current sample.

\section{Depression}

The Beck Depression Inventory-II (BDI-II; Beck, Steer, \& Brown, 1996) is a self-report measure of depressive symptoms with 21 items which are rated on Likert-type scale (rated 0 to 3). The BDI-II has demonstrated good psychometric properties (Dozois, Dobson, \& Ahnberg, 1998). The internal consistency was adequate for the BDI-II (Cronbach's $\alpha=.91)$ in the current sample. 


\section{Behavioral Assessment of Social Anxiety and Behavior}

A behavioral assessment was used to assess social behaviors and anxiety at pre- and posttreatment. The two in-vivo social interaction tasks included an adapted Unstructured Conversation Task (UCT; Turner, Beidel, Cooley, \& Woody, 1994) and an Impromptu Speech Task (IST; Beidel et al., 2010). Each participant rated their level of anxiety immediately following each task using a 9-point Likert-type rating scale (0 to 8; no distress to extreme distress). Behavioral assessments were video and audio recorded and behaviors were coded by independent raters (blinded to treatment condition and time of assessment) using the Noldus Observer XT (Version 10.1; Noldus Information Technology, 2010). Briefly, the Noldus Observer XT software allows for the coding of behaviors at various playback speeds with exact precision (in hundredths of seconds). The Observer XT provides an output with the duration and frequency of each behavior, which can then be used for statistical analyses and comparisons.

UCT. The UCT involved a 5-minute social interaction during which participants were given one of two scenarios, which was randomly selected at pre-treatment. The unused scenario was given during the post-treatment UCT. The two scenarios were a) moving into a new house and meeting a new neighbor and b) meeting someone at a dinner party. Participants were instructed to “get to know [the confederate] by having a conversation with him/her”. In these unstructured tasks, confederates were trained to respond to the participant in a pleasantly neutral manner without leading the conversation, and the sex of the confederate was randomized for each assessment. Social behaviors were coded using the Noldus Observer XT as the total duration (in seconds) of each participant's eye/facial gaze and time spent speaking during the UCT. Additionally, the participants' self-reported anxiety during the task was recorded using the 9-point Likert-type scale described above. 
IST. The IST required participants to prepare a 10-minute speech and deliver it to an audience of five confederates. Participants were given three minutes to prepare the speech using a maximum of three out of five topics provided by the experimenter. Participants were allowed to terminate the speech after three minutes by holding up a "stop card", if the distress from speaking became too great. Social behaviors were coded, using the Noldus Observer XT, as the total duration (in seconds) of each participant's time spent speaking, eye/facial gaze, and time before requesting to end the task during the IST. Escape behavior (i.e., requesting to end the task early) was also coded. Additionally, the participants' self-reported anxiety during the task was recorded using the 9-point Likert-type scale described above.

\section{Treatment Credibility}

Three questions regarding treatment credibility (adapted from Borkovec \& Nau, 1972) were administered following the second treatment session. These measures assessed confidence in treatment, perception of logicalness of treatment, and confidence in recommending the treatment to a friend. Responses were rated on a 3-point Likert-type scale (0 to 3; not at all to very much).

\section{Treatment}

Materials. Faces used for the treatment program were selected from a standardized set of emotional expressions (Matsumoto \& Ekman, 1989). The set includes pictures of faces of eight individuals (four men and four women) displaying neutral and negative/threatening (i.e., disgust) expressions. Pictures were centered horizontally $17.5 \mathrm{~cm}$ from the left edge of the screen and 3.0 $\mathrm{cm}$ from the top of the screen, and there was a $1.5 \mathrm{~cm}$ gap between the bottom of the top image and the top of the bottom image. Pictures were presented against a static light grey background via LCD computer monitor. Trials were conducted using E-Prime Professional 2.0 (Psychology 
Software Tools, Inc., Sharpsburg, PA). An independent research assistant created desktop links to each condition that were masked by ambiguous names (e.g., "Skinner" or "Jung") to blind clinicians and participants to treatment condition. These ambiguous names were entered next to the participants' names on a tracking sheet to ensure that their assigned treatment was administered.

Attention Training. The attention training protocol mirrored that conducted by Amir et al. (2009) and Schmidt et al. (2009), who used a modified dot-probe paradigm originally designed by MacLeod et al. (1986). Each trial began with the presentation of a fixation cross (“+”) in the center of the monitor for 500ms. Two faces of the same individual were then presented (one on top and one on bottom) for 500ms. Each pair of faces displayed one of two combinations of emotions (i.e., neutral and disgust, or neutral and neutral). Following this presentation, a probe (the letter $E$ or $F$ ) replaced one of the two faces, and participants pressed the corresponding button (right or left) on the computer mouse to identify either a probe of $E$ or $F$. A new trial began following the participants' response. During each session, participants observed a total of 160 trials, 128 (80\%) of which included the presentation of the probe in place of a neutral face: 2 (disgust face position: top or bottom) $\times 2$ (probe type: $E$ or $F) \times 8$ (person) $\times$ 4 (repetition). The remaining 32 (20\%) trials included only neutral faces: 2 (probe type: $E$ or $F$ ) $\times$ 2 (probe position: top or bottom) $\times 8$ (person).

Attention Control. The AC condition replicated the AT condition with the exception of the frequency in which the probe appeared in the place of neutral expressions rather than those of disgust. A total of 160 trials were conducted and included 64 trials (40\%; neutral-disgust) where the probe replaced the disgust face, 64 trials (40\%; neutral-disgust) where the probe replaced the neutral face, and 32 trials (20\%) where only neutral faces were presented. 


\section{RESULTS}

\section{Statistical Analyses}

Preliminary analyses indicated that participants in the two treatment conditions did not differ significantly on any outcome measure at pre-treatment. Post-treatment data were complete for all participants with the exception of behavioral data for one participant in the AT condition who completed all treatment sessions and post-treatment assessment measures but refused to participate in the behavioral assessment at post-treatment (See Figure 1). The intention-to-treat approach was used for this participant when analyzing post-treatment behavioral assessment data. Analysis of covariance (ANCOVA) was used to compare post-treatment scores while co-varying for pre-treatment scores, as recommended by Van Bruekelen (2006). Chi square and analysis of variance (ANOVA) were used to examine differences between groups for variables which were categorical (i.e., treatment responder status, escape during the speech task) or had no pretreatment scores (i.e., CGI-Improvement scores, treatment credibility). Means, standard deviations, and between-group effect sizes for outcome variables are displayed in Table 2. 


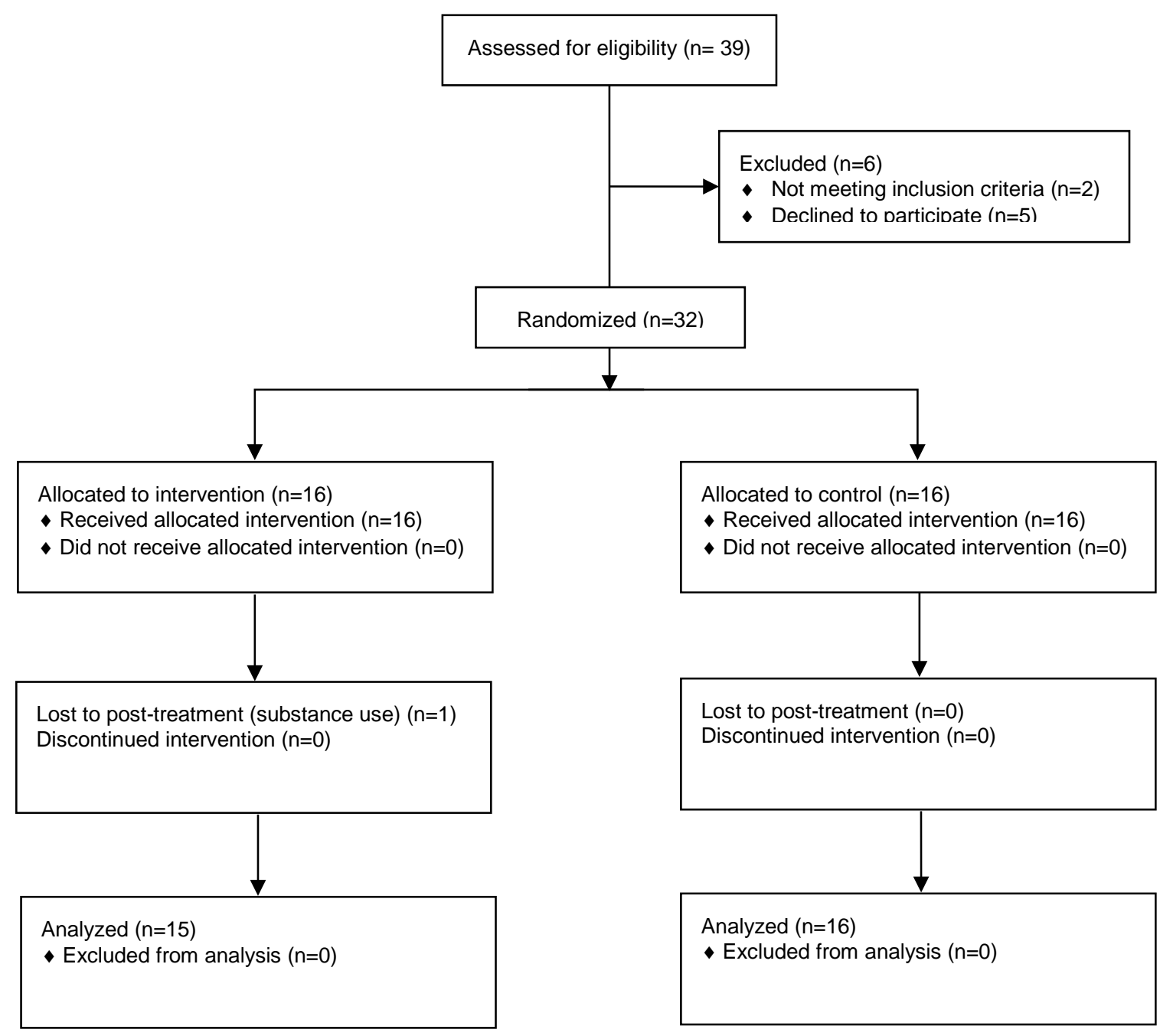

Figure 1

Consort Diagram

\section{Diagnosis and Severity at Post-Treatment}

All participants met DSM-IV-TR diagnostic criteria for SAD at post-treatment. Scores on the CGI-Improvement scale were not significantly different between the two conditions, $F(1,29)$ $=.151, \mathrm{p}=.701, \eta \mathrm{p} 2=.005$. One participant in the AT condition $(6.7 \%)$ was classified as a treatment responder (i.e., received a score of 1 or 2 on the CGI-Improvement scale) whereas no participants in the AC condition were classified as a responder, a difference that was not statistically significant, $\chi^{2}(1,31)=1.102, p=.294, \Phi=.189$. Consistently, participants in the 
two treatment conditions did not differ significantly at post-treatment on CGI-Severity scores, $F(1,28)=.315, p=.579, \eta_{\mathrm{p}}^{2}=.011$, or BARS ratings, $F(1,28)=.127, p=.724, \eta_{\mathrm{p}}^{2}=.005$.

\section{Social Anxiety}

Clinician-rated measure. Participants in the two treatment conditions did not differ significantly at post-treatment on BSPS scores, $\mathrm{F}(1,28)=.034, \mathrm{p}=.856, \eta \mathrm{p} 2=.001$.

Self-report measures. Participants in the two treatment conditions did not differ significantly at post-treatment on SPAI, $F(1,28)=.748, p=.394, \eta_{\mathrm{p}}{ }^{2}=.026$, or LSAS-SR scores, $F(1,28)=2.343, p=.138, \eta_{\mathrm{p}}^{2}=.080$.

\section{Depression}

Participants in the two treatment conditions did not differ significantly at post-treatment on BDI-II scores, $\mathrm{F}(1,28)=.654, \mathrm{p}=.426, \eta \mathrm{p} 2=.023$.

\section{Behavioral Assessment of Anxiety and Social Behavior}

Anxiety level during social interactions. Participants in the two treatment conditions did not differ significantly at post-treatment on self-reported anxiety during the UCT, $F(1,28)$ $=.315, p=.579, \eta_{\mathrm{p}}^{2}=.011$, or the IST, $F(1,28)=.058, p=.812, \eta_{\mathrm{p}}^{2}=.002$.

Social behaviors during social interactions. For the $U C T$, there were no significant differences between treatment conditions on the percent of time making eye/facial gaze during the task, $F(1,28)=3.452, p=.074, \eta_{\mathrm{p}}{ }^{2}=.110$. The two conditions did differ significantly on the duration of time speaking during the task. Participants in the AT condition spoke significantly longer $(55.25 \%$ of time in the task) than those in the AC condition $(51.90 \% ; d=.20), F(1,28)=$ 4.454, $p=.044, \eta_{\mathrm{p}}^{2}=.137$.

For the IST, participants in the two treatment conditions did not differ significantly at post-treatment on the percent of time making eye/facial gaze during the task, $F(1,28)=1.348, p$ 
$=.255, \eta_{\mathrm{p}}{ }^{2}=.046$. The two conditions did differ significantly on the duration of time speaking during the task. Participants in the AC condition spoke significantly longer (89.33\% of the time in the task) than those in the AT condition (84.82\%, $d=.28), F(1,28)=4.395, p=.045, \eta_{\mathrm{p}}{ }^{2}$ $=.136$. Some participants did not speak at all but stood silently before ending the task. Escape was defined as the number of participants who requested to end the IST early due to overwhelming anxiety. Results of the chi square test revealed no group difference in the number of participants who escaped the IST (86.7\% versus $100 \%$ for the AT and AC conditions, respectively; $\left.\chi^{2}[1,31]=2.280, p=.131, \Phi=.271\right)$. The groups also did not differ significantly on the length of time they remained in the task prior to escape, $F(1,28)=1.012, p=.323, \eta_{p}{ }^{2}$ $=.035$.

\section{Treatment Credibility}

Participants in the two treatment conditions did not differ significantly on how confident they were in treatment, $\mathrm{F}(1,27)=.063, \mathrm{p}=.804, \eta \mathrm{p} 2=.002$, how logical the treatment seemed to them, $\mathrm{F}(1,27)=.127, \mathrm{p}=.847, \eta \mathrm{p} 2=.064$, or how confident they would be in recommending the treatment to a friend, $\mathrm{F}(1,27)=.441, \mathrm{p}=.512, \eta \mathrm{p} 2=.016$. 
Table 2

Means and standard deviations of study outcome variables at pre- and post-treatment

\begin{tabular}{|c|c|c|c|c|c|}
\hline & \multicolumn{2}{|c|}{ Pre } & \multicolumn{2}{|c|}{ Post } & \multirow[b]{3}{*}{$d$} \\
\hline & $\mathrm{AT}$ & $\mathrm{AC}$ & $\mathrm{AT}$ & $\mathrm{AC}$ & \\
\hline & $\mathrm{M}(S D)$ & $\mathrm{M}(S D)$ & $\mathrm{M}(S D)$ & $\mathrm{M}(S D)$ & \\
\hline \multicolumn{6}{|l|}{ Severity } \\
\hline CGI-S & $5.20(.86)$ & $5.19(.75)$ & $4.67(.90)$ & $4.81(.54)$ & .19 \\
\hline CGI-I & - & - & $3.67(.72)$ & $3.75(.44)$ & .13 \\
\hline BARS & $4.27(.80)$ & $4.13(.80)$ & $3.87(.99)$ & $3.88(.95)$ & .01 \\
\hline \multicolumn{6}{|l|}{ Social Anxiety } \\
\hline BSPS & $48.73(8.59)$ & $48.43(8.51)$ & 43.66 (9.31) & 42.93 (11.18) & .07 \\
\hline SPAI & 106.80 (15.48) & $111.24(23.75)$ & 86.36 (28.88) & 95.81 (19.38) & .38 \\
\hline LSAS-SR & $86.66(18.25)$ & $76.80(22.21)$ & $59.93(20.01)$ & 66.37 (22.67) & .30 \\
\hline \multicolumn{6}{|l|}{ Depression } \\
\hline BDI-II & $16.00(10.88)$ & $15.31(11.06)$ & $11.93(10.84)$ & $14.06(11.33)$ & .19 \\
\hline \multirow{2}{*}{\multicolumn{6}{|c|}{$\begin{array}{l}\text { Behavioral Assessment } \\
\text { UCT }\end{array}$}} \\
\hline & & & & & \\
\hline Anxiety & $5.40(1.59)$ & $5.43(2.06)$ & $3.20(2.24)$ & $3.56(1.36)$ & .19 \\
\hline Eye-gaze (\%) & $45.22(18.21)$ & 49.27 (17.83) & 52.32 (19.10) & $57.61(22.03)$ & .25 \\
\hline Speaking (\%) & 38.93 (17.01) & 45.15 (14.33) & 55.25 (16.15) & $51.90(16.94)$ & .20 \\
\hline \multicolumn{6}{|l|}{ IST } \\
\hline Anxiety & $6.73(2.01)$ & $6.56(1.75)$ & $5.20(2.21)$ & $4.93(1.95)$ & .13 \\
\hline Eye-gaze (\%) & 36.37 (24.83) & 40.28 (22.96) & 32.60 (20.28) & 42.96 (29.74) & .40 \\
\hline Speaking (\%) & 80.51 (19.73) & 73.05 (22.64) & 84.82 (16.54) & 89.33 (14.97) & .28 \\
\hline Before escape(s) & 272.01 (161.92) & 236.62 (109.92) & 346.47 (167.55) & 278.73 (132.10) & .45 \\
\hline \multicolumn{6}{|l|}{ Credibility } \\
\hline Confidence & - & - & $.85(.66)$ & $.80(.56)$ & .08 \\
\hline Logicalness & - & - & $.71(.72)$ & $.40(.50)$ & .50 \\
\hline Recommend & - & - & $.93(.61)$ & $.80(.41)$ & .25 \\
\hline
\end{tabular}

Note. CGI-S = Clinical Global Impressions-Severity (Guy, 1976); CGI-I = Clinical Global

Impressions-Improvement (Guy, 1976); BARS Behavioral Avoidance Rating Scale (Beidel et al., 2007); BSPS = Brief Social Phobia Scale (Davidson et al., 1991); SPAI = Social Phobia and

Anxiety Inventory (Turner et al., 1989; Turner, Beidel, \& Dancu, 1996); LSAS-SR = Liebowitz Social Anxiety Scale-Self Report (Liebowitz, 1987); BDI-II = Beck Depression Inventory-II

(Beck, Steer, \& Brown, 1996); UCT = Unstructured Conversation Task (Turner, Beidel, Cooley, Woody, \& Messer, 1994); IST = Impromptu Speech Task (Beidel et al., 2010). $d=$ Cohen’s $d$. $d$ was calculated as between group effect size at post-treatment and does not account for variation in pre-treatment scores. 


\section{DISCUSSION}

This was the first study to explicitly replicate previous methodology for attention training for social anxiety (Amir et al., 2009; Schmidt et al., 2009) but also expand the assessment of patient outcome to include behavioral assessment. The results of this investigation revealed that all participants met DSM-IV-TR criteria for SAD at post-treatment despite treatment condition. Consistently, scores on the SPAI did not differ between the two conditions at post-treatment, even when accounting for pre-treatment differences. Finally, between-group differences on selfreported anxiety and blinded observer ratings of social behavior during in-vivo social interactions (i.e., the UCT and IST) were not observed. No differences were found for social skill variables such as eye/facial gaze, time before escape, or the number of participants who escaped during the IST. Only two behavioral indices indicated group differences, although the results did not favor one group over the other.

With regard to diagnosis at post-treatment, it was expected that some participants in the AT condition would no longer meet criteria for SAD given rates of recovery reported in prior investigations (i.e., Amir et al., 2009; Schmidt et al., 2009) yet this was not the case in this investigation. Although we used a different diagnostic interview, diagnoses were reliable and accurate, as reflected by high inter-rater reliability. During post-treatment diagnostic interviews, all participants reported experiencing considerable distress and avoidance in social situations, few reported noticing positive change in their condition, and all participants requested additional treatment. Furthermore, data from clinician- and self-report measures revealed no group differences on any measures (i.e., the BSPS, SPAI, and LSAS-SR). Average scores on self-report measures at post-treatment fell at or above the recommended cutoff criteria for probable SAD (approximately 60 for the LSAS-SR [Rytwinski et al., 2009] and the SPAI [Turner, Beidel \& 
Dancu, 1996]). Post-treatment between-group differences on these measures were smaller than those observed in the Amir et al. (2009) investigation, as reflected by between-group effect sizes at post-treatment $(d=.30$ to .38$)$.

A close perusal of Table 2 reveals decreases on all measures for both treatment conditions. This is to be expected, though, considering non-specific treatment effects that might occur simply from attending therapy (e.g., the development of patient-therapist relationships; see Patterson [1985] for a review of therapist-related variables associated with non-specific treatment effects) and underscores the need for placebo control conditions in randomized controlled trials. In some instances, decreases in symptomology may shift a patient's status to the extent that he/she no longer experiences functional impairment even if occasional fears/worries remain. However, in this investigation decreases in symptom severity did not result in a loss of diagnosis for any patients, suggesting all participants were still functionally impaired.

The addition of a behavioral assessment of social anxiety and social behavior is unique to this investigation and provides an important clinical perspective on patient functioning. In particular, rather than examining solely statistically significant changes on self-report measures of patient functioning, clinically significant change in real-world functioning may be more closely examined (Kazdin, 1999). Significant differences between groups on speech duration during the two tasks were found at post-treatment, although these differences did not favor one group over the other (i.e., the AT group spoke longer during the UCT and the AC group spoke longer during the IST; see Figure 2). However, between group effect sizes at post-treatment were small (i.e., $d=.20$ to .28 ), suggesting that any gains were minimal. 


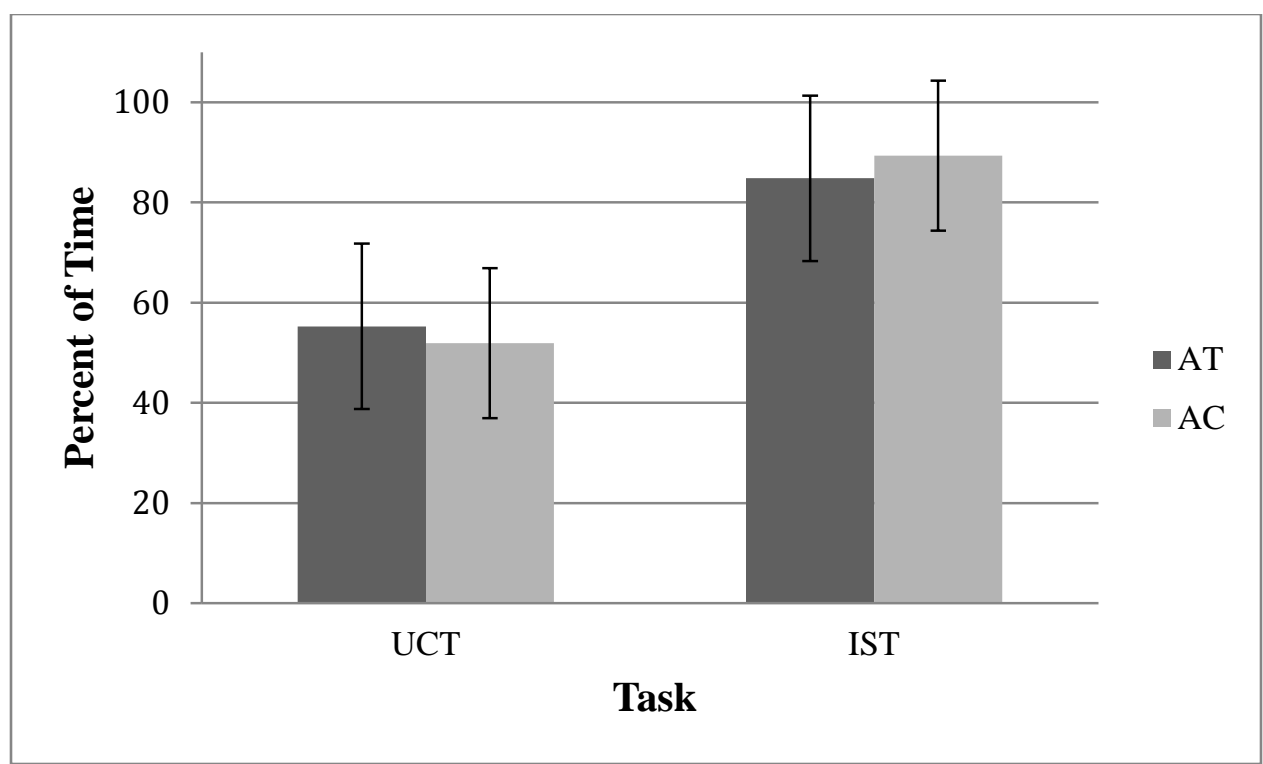

Figure 2

Percent of time speaking during the post-treatment behavioral assessment

Another unique aspect of this investigation is the assessment of participants’ perception of treatment credibility. In addition to the lack of group difference, both groups endorsed low ratings with regard to their confidence in the treatment, the logicalness of the treatment, and the likelihood that they would recommend the treatment to a friend. This low confidence, of course, could be related to the lack of treatment outcome, although the similarly low levels of confidence reported by both groups suggests that confidence did not relate to the lack of differential between-group effects for the treatment.

\section{Implications}

The results of the current investigation do not support the efficacy of attention training for the treatment of SAD and are consistent with other recent investigations finding negative effects for modified versions of this treatment (Boettcher et al., 2011; Carlbring et al., 2012; Heeren et al., 2012; Neubauer et al., 2012). Consistent with Emmelkamp (2012)'s statement that “there is no robust evidence that attention training is of clinical value," the results of this study provide further support for this claim. Why the positive response of the initial investigations has 
not withstood the test of replication is unclear but merits further research. Given the significant prevalence of this disorder, establishing the efficacy of a range of interventions remains an important goal of clinical research. Furthermore, efficacious interventions that may be administered by sub-doctoral level clinicians are necessary. At this time, there are questions regarding the ability of attentional training therapies to deliver their initial promise.

\section{Limitations}

There are several limitations of this investigation. First, the limited sample size raises concerns regarding the adequacy of power to detect significant differences across groups. However, an a priori power analysis using power of .80 and a medium effect size indicated that the current sample would be acceptable for the planned analyses. Furthermore the current study's sample size $(n=31)$ exceeded that of others (e.g., Schmidt et al., 2009) at follow-up $(n=26)$, the only time-point at which significant differences between groups were observed. Second, the demographics of the current sample appear to differ somewhat from those of Amir et al. (2009). Particularly, the average age of the current sample was somewhat younger and slightly more diverse with respect to race/ethnicity. It is possible that these differences may have affected the credibility of computer-based intervention modalities and hence their effectiveness, although the interplay of these factors has yet to be studied for this intervention. Third, the generalizability of this study's behavioral assessment as an analogue for day-to-day social interactions may appear limited. However, decades of research affirm the ability of these tasks to approximate in-vivo interactions and in this study the tasks elicited a significant level of anxiety in the participants. Clearly, behavioral assessment is an important tool in understanding functional impairment relative to various psychopathologies, particularly SAD. 


\section{Conclusion}

This study was an attempt to replicate previous investigations of attention training as a treatment for adult SAD (i.e., Amir et al., 2009; Schmidt et al., 2009) using a multimodal assessment of patient functioning. Consistent with other studies investigating modified versions

of this protocol, we were unable to replicate the positive results of these initial investigations based on either patient- or clinician-report, as well as behavioral assessment of social functioning. Future investigations should seek to further elucidate the exact mechanisms by which these treatments may affect levels of social anxiety in patients with SAD. 
APPENDIX A: IRB APPROVAL LETTER 
University of Central Florida Institutional Review Board Office of Research \& Commercialization 12201 Research Parkway, Suite 501

Orlando, Florida 32826-3246

Telephone: 407-823-2901 or 407-882-2276

www.research.ucf.edu/compliance/irb.html

\section{Approval of Human Research}

\section{From: $\quad$ UCF Institutional Review Board \#1 \\ FWA00000351, IRB00001138}

To: $\quad$ Brian E. Bunnell and Co-PI: Deborah Casamassa Beidel

Date: $\quad$ June 15, 2012

Dear Researcher:

On 6/15/2012, the IRB approved the following human participant research until 6/14/2013 inclusive:

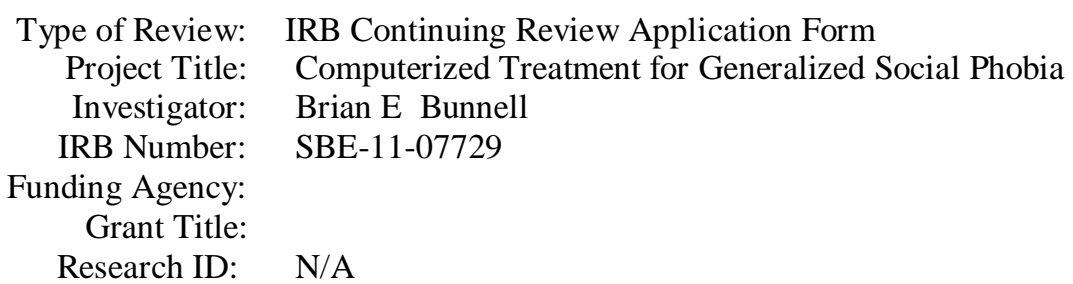

The Continuing Review Application must be submitted 30days prior to the expiration date for studies that were previously expedited, and 60 days prior to the expiration date for research that was previously reviewed at a convened meeting. Do not make changes to the study (i.e., protocol, methodology, consent form, personnel, site, etc.) before obtaining IRB approval. A Modification Form cannot be used to extend the approval period of a study. All forms may be completed and submitted online at https://iris.research.ucf.edu .

If continuing review approval is not granted before the expiration date of 6/14/2013, approval of this research expires on that date. When you have completed your research, please submit a Study Closure request in iRIS so that IRB records will be accurate.

Use of the approved, stamped consent document(s) is required. The new form supersedes all previous versions, which are now invalid for further use. Only approved investigators (or other approved key study personnel) may solicit consent for research participation. Participants or their representatives must receive a copy of the consent form(s).

In the conduct of this research, you are responsible to follow the requirements of the Investigator Manual.

On behalf of Sophia Dziegielewski, Ph.D., L.C.S.W., UCF IRB Chair, this letter is signed by:

Signature applied by Joanne Muratori on 06/15/2012 10:35:03 AM EDT

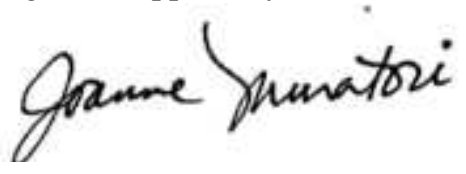

IRB Coordinator 


\section{REFERENCES}

American Psychiatric Association. (2000). Diagnostic and statistical manual of mental disorders (Revised 4th ed.). Washington, DC: Author.

Amir, N., Beard, C., Taylor, C., Klumpp, H., Elias, J., Burns, M., \& Chen, X. (2009). Attention training in individuals with generalized social phobia: A randomized controlled trial. Journal of Counseling and Clinical Psychology, 77, 961-973. DOI: 10.1037/a0016685

Amir, N., Klumpp, H., Elias, J., Bedwell, J., Yanasak, N., \& Miller, S. (2005). Increased activation of the anterior cingulate cortex during Processing of disgust faces in individuals with social phobia. Biological Psychiatry, 57, 975-981.

DOI:10.1016/j.biopsych.2005.01.044

Amir, N., Elias, J., Klumpp, H., \& Przeworski, A. (2003). Attentional bias to threat in social phobia: Facilitated processing of threat or difficulty disengaging attention from threat? Behaviour Research and Therapy, 41, 1325-1335. DOI: 10.1016/j.brat.2003.08.001

Asmundson, G. G., \& Stein, M. B. (1994). Selective processing of social threat in patients with generalized social phobia: Evaluation using a dot-probe paradigm. Journal of Anxiety Disorders, 8(2), 107-117. doi:10.1016/0887-6185(94)90009-4

Baker, S. L., Heinrichs, N., Kim, H. J., \& Hofmann, S. G. (2002) The Liebowitz Social Anxiety Scale as a self-report instrument: A preliminary psychometric analysis. Behaviour Research and Therapy, 40, 701-715. DOI: 10.1016/S0005-7967(01)00060-2,

Beck, A. T., Emery, G., \& Greenberg, R. (1985). Anxiety disorders and phobias: A cognitive perspective. New York: Basic Books.

Beck, A. T., Steer, R. A., \& Brown, G. K. (1996). Manual for Beck Depression Inventory: II. San Antonio, TX: Psychological Corporation. 
Becker, E. S., Rinck, M., Margraf, J., \& Roth, W. T. (2001). The emotional stroop effect in anxiety disorders general emotionality or disorder specificity? Journal of Anxiety Disorders, 15, 147- 159. DOI: http://dx.doi.org/10.1016/S0887-6185(01)00055-X

Beidel, D. C., Rao, P. A., Scharfstein, L. A., Wong, N., \& Alfano, C. A. (2010). Social skills and social phobia: An investigation of DSM-IV subtypes. Behaviour Research and Therapy, 48(10), 992-1001. DOI: 10.1016/j.brat.2010.06.005

Beidel, D. C., Turner, S. M., Stanley, M. A., \& Dancu, C. V. (1989). The Social Phobia and Anxiety Inventory: Concurrent and external validity. Behavior Therapy, 20, 417-427. DOI: 10.1016/S0005-7894(89)80060-7

Beidel, D. C., \& Turner, S. M. (1998). Shy children, phobic adults: The nature and treatment of social phobia. Washington DC: American Psychological Association Books.

Beidel, D. C., Turner, S. M., Sallee, F. R., Ammerman, R. T., Crosby, L. A., \& Pathak, S. (2007). SET-C versus fluoxetine in the treatment of childhood social phobia. Journal of the American Academy of Child and Adolescent Psychiatry, 46(12), 1622-1632. DOI: 10.1097/chi.0b013e318154bb57

Boettcher, J., Berger, T., \& Renneberg, B. (2012). Internet-based attention training for social anxiety: A randomized controlled trial. Cognitive Therapy and Research, 36(5), 522-536. doi:10.1007/s10608-011-9374-y

Borkovec, T. D., \& Nau, S. D. (1972). Credibility of analogue therapy rationales. Journal of Behavior Therapy and Experimental Psychiatry, 3(4), 257-260. doi:10.1016/00057916(72)90045-6

Bradley, B. P., Mogg, K., \& Millar, N. M. (1999). Covert and overt orienting of attention to emotional faces in anxiety. Cognition and Emotion, 14, 789-808. DOI: 
$10.1080 / 02699930050156636$

Bradley, B. P., Mogg, K., Millar, N., Bonham-Carter, C., Fergusson, E., Jenkins, J., \& Parr, M. (1997). Attentional biases for emotional faces. Cognition and Emotion, 11, 25-42. DOI: $10.1080 / 026999397380014$

Brown, T. A., Di Nardo, P. A., \& Barlow, D. H. (1994). Anxiety Disorders Interview Schedule for DSM-IV (ADIS-IV). San Antonio, TX: Psychological Corporation/Graywind Publications Incorporated.

Bunnell, B. E., Joseph, D. L., \& Beidel, D. C. (2012). Measurement invariance of the Social Phobia and Anxiety Inventory. Journal of Anxiety Disorders, DOI: 10.1016/j.janxdis.2012.09.001

Calamaras, M. R., Tone, E. B., \& Anderson, P. L. (2012). A pilot study of attention bias subtypes: Examining their relation to cognitive bias and their change following cognitive behavioral therapy. Journal of Clinical Psychology, 68(7), 745-754. DOI: 10.1002/jclp.21875

Carlbring, P., Löfqvist, M., Sehlin, H., Amir, N., Rousseau, A., Hofmann, S., \& Andersson, G. (2012). Internet-delivered attention bias modification training in individuals with social anxiety disorder - a double blind randomized controlled trial. BMC Psychiatry, 12(66), 19. DOI: $10.1186 / 1471-244 X-12-66$

Chen, Y. P., Ehlers, A., Clark, D. M., \& Mansell, W. (2002). Participants with generalized social phobia direct their attention away from their faces. Behaviour and Research Therapy, 40, 677-687. DOI: http://dx.doi.org/10.1016/S0005-7967(01)00086-9

Clark, D. B. (1993). Assessment of social anxiety in adolescents. Paper presented at the Anxiety Disorders Association of America Annual Convention, Charleston, SC, March 19-21. 
Clark, D. M., \& Wells, A. (1995). A cognitive model of social phobia. In: R. G. Heimberg, M. R. Liebowitz, D. A. Hope, \& F. R. Schneier (Eds.), Social phobia: Diagnosis, assessment, and treatment (pp. 69-93). New York: Guilford Press.

Costello, E. J., Egger, H. L., \& Angold, A. (2004). Developmental epidemiology of anxiety disorders. In: Ollendick, T. H., March, J. S., (Eds.) Phobic and anxiety disorders in children and adolescents: A clinician's guide to effective psychosocial and pharmacological interventions (pp. 61-91). New York, NY: Oxford.

Costello, E., Egger, H., \& Angold, A. (2005). 10-Year Research Update Review: The Epidemiology of Child and Adolescent Psychiatric Disorders: I. Methods and Public Health Burden. Journal of the American Academy of Child \& Adolescent Psychiatry, 44(10), 972-986. doi:10.1097/01.chi.0000172552.41596.6f

Costello, E. J., Mustillo, S., Erkanli, A., Keeler, G., \& Angold, A. (2003). Prevalence and development of psychiatric disorders in childhood and adolescence. Archives of General Psychiatry, 60, 837-844. DOI: 10.1001/archpsyc.60.8.837

Davidson, J. R., Potts, N. L., Richichi, E. A., \& Ford, S. M. (1991). The Brief Social Phobia Scale. Journal of Clinical Psychiatry, 52(Suppl), 48-51.

DeWit, D. J., Ogborne, A., Offord, D. R., \& MacDonald, K. (1999). Antecedents of the risk of recovery from DSM-III-R social phobia. Psychological Medicine, 29, 569-582.

Dozois, D. J. A., Dobson, K. S., \& Ahnberg, J. L. (1998). A psychometric evaluation of the Beck Depression Inventory-II. Psychological Assessment, 10(2), 83-89. DOI: 10.1037/10403590.10.2.83

Emmelkamp, P. M. G. (2012). Attention bias modification: the Emperor's new suit? BMC Medicine, 10(63), 1-3. DOI: 10.1186/1741-7015-10-63 
Eysenck, M. (1997). Anxiety and cognition: A unified theory. Hove: Psychology Press Ltd.

Fresco, D. M., Coles, M. E., Heimberg, R. G., Liebowitz, M. R., Hami, S., Stein, M. B., \& Goetz, D. (2001). The Liebowitz Social Anxiety Scale: A comparison of the psychometric properties of self-report and clinician-administered formats. Psychological Medicine, 31, 1025-1035. DOI: 10.1017/S0033291701004056

Gamble, A. L., \& Rapee, R. M. (2010). The time-course of attention to emotional faces in social phobia. Journal of Behavioral and Experimental Psychiatry, 41, 39-44. DOI: 10.1016/j.jbtep.2009.08.008

Garner, M., Mogg, K., Bradley, B. P. (2006). Orienting and maintenance of gaze to facial expressions in social anxiety. Journal of Abnormal Psychology, 115, 760-770.

DOI: 10.1037/0021-843X.115.4.760

Grant, B. F., Stinson, F. S., Hasin, D. S., Dawson, D. A., Chou, S., Ruan, W., \& Huang, B. (2005). Prevalence, Correlates, and Comorbidity of Bipolar I Disorder and Axis I and II Disorders: Results From the National Epidemiologic Survey on Alcohol and Related Conditions. Journal of Clinical Psychiatry, 66(10), 1205-1215. doi:10.4088/JCP.v66n1001

Guy, W. (1976). ECDEU Assessment Manual for Psychopharmacology. Washington, DC: DHEW.

Heeren, A., Reese, H. E., McNally, R. J., \& Philippot, P. (2012). Attention training toward and away from threat in social phobia: Effects on subjective, behavioral, and physiological measures of anxiety. Behaviour Research and Therapy, 50, 30-39. DOI 10.1007/s10608011-9374-y. DOI: 10.1016/j.brat.2011.10.005

Heimberg, R. G., Stein, M. B., Hiripi, E., \& Kessler, R. C. (2000). Trends in the prevalence of 
social phobia in the United States: A synthetic cohort analysis of changes over four decades. European Psychiatry, 15(1), 29-37. DOI: 10.1016/S0924-9338(00)00213-3

Holle, C., Neely, J. H., \& Heimberg, R. G. (1997). The effects of blocked versus random presentation and semantic relatedness of stimulus words on response to a modified stroop task among social phobics. Cognitive Therapy and Research, 21, 681-697. DOI: 10.1023/A:1021860324879

Hope, D. A., Rapee, R. M., Heimberg, R. G., \& Dombeck, M. J. (1990). Representations of the self in social phobia: Vulnerability to social threat. Cognitive Therapy and Research, 14, 177-189. DOI: 10.1007/BF01176208

Kazdin, A. E. (1999). The meanings and measurement of clinical significance. Journal of Consulting and Clinical Psychology, 67(3), 332-339. doi:10.1037/0022-006X.67.3.332

Kessler, R.C. (2003). The impairments caused by social phobia in the general population: implications for intervention. Acta Psychiatrica Scandinavica, 108, 19-27. DOI: 10.1034/j.1600-0447.108.s417.2.x

Lecrubier, Y. (1998). Comorbidity in social anxiety disorder: Impact on disease burden and management. Journal of Clinical Psychiatry, 59, 33-37.

Liebowitz, M. R. (1987). Social phobia. Modern Problems of Pharmacopsychiatry, 22, 141-173. Macleod, C., Mathews, A., \& Tata, P. (1986). Attentional bias in emotional disorders. Journal of Abnormal Psychology, 95, 15-20. DOI: 10.1037/0021-843X.95.1.15

Maidenberg, E., Chen, E., Craske, M., Bohn, P., \& Bystritsky, A. (1996). Specificity of attentional bias in panic disorder and social phobia. Journal of Anxiety Disorders, 6, 529541. DOI: http://dx.doi.org/10.1016/S0887-6185(96)00028-X

Mansell, W., Clark, D. M., Ehlers, A., \& Chen, Y. (1999). Social anxiety and attention away 
from emotional faces. Cognition and Emotion, 13, 673-690.

DOI:10.1080/026999399379032

Mansell, W., Ehlers, A., Clark, D. M., \& Chen, Y. (2002). Attention to positive and negative social-evaluative words: Investigating the effects of social anxiety and social threat. Anxiety, Stress, and Coping, 15, 19-29. DOI:10.1080/10615800290007263

Matsumoto, D., \& Ekman, P. (1989). The Japanese and Caucasian facial expressions of emotion (JACFEE) and neutrals (JACNeuF). San Francisco: San Francisco State University, Department of Psychology, Intercultural and Emotion Research Laboratory.

Mattia, J. I., Heimberg, R. G., \& Hope, D. A. (1993). The revised Stroop color-naming task in social phobics. Behaviour Research and Therapy, 31(3), 305-313. doi:10.1016/00057967(93)90029-T

McNeil, D. W., Ries, B. J., Taylor, L. J., Boone, M. L., Carter, L. E., Turk, C. L., \& Lewin, M. R. (1995). Comparison of social phobia subtypes using stroop tests. Journal of Anxiety Disorders, 9, 47-57. DOI: http://dx.doi.org/10.1016/0887-6185(94)00027-8

Mogg, K., \& Bradley, B. P. (1998). A cognitive-motivational analysis of anxiety. Behaviour Research and Therapy, 36, 809-848. DOI: http://dx.doi.org/10.1016/S00057967(98)00063-1

Mogg, K., \& Bradley, B. P. (2002). Selective orienting of attention to masked threat faces in social anxiety. Behaviour and Research Therapy, 40, 1403-1414. DOI: http://dx.doi.org/10.1016/S0005-7967(02)00017-7

Mogg, K., Philippot, P., \& Bradley, B. P. (2004). Selective Attention to Angry Faces in Clinical Social Phobia. Journal Of Abnormal Psychology, 113(1), 160-165. doi:10.1037/0021843X.113.1.160 
Neubauer, K., von Auer, M., Murray, E., Petermann, F., Helbig-Lang, S., \& Gerlach, A. L. (In Press). Internet-delivered attention modification training as a treatment for social phobia: A randomized controlled trial. Behaviour Research and Therapy.

Noldus Information Technology. (2010). The Observer XT (Version 10.1) [Computer Software]. Wageningen, The Netherlands Noldus Information Technology.

Ononaiye, M. S. P., Turpin, G., \& Reidy, J. G. (2007). Attentional bias in social anxiety: Manipulation of stimulus duration and social-evaluation anxiety. Cognitive Therapy and Research, 31, 727-740. DOI: 10.1007/s10608-006-9096-8

Patterson, C. H. (1985). What is the placebo of psychotherapy? Psychotherapy: Theory, Practice, Training, 22(2), 163-169. DOI: 10.1037/h0085489

Pineles, S. L., \& Mineka, S. (2005). Attentional bias to internal and external sources of potential threat in social anxiety. Journal of Abnormal Psychology, 114, 314-318. DOI: 10.1037/0021-843X.114.2.314

Pishyar, R., Harris, L. M., \& Menzies, R. G. (2004). Attentional bias for words and faces in social anxiety. Anxiety, Stress, and Coping, 1, 23-36. DOI: $10.1080 / 10615800310001601458$

Pishyar, R., Harris, L. M., \& Menzies, R. G. (2008). Responsiveness of measures of attentional bias to clinical change in social phobia. Cognition and Emotion, 22, 12091227. DOI: $10.1080 / 02699930701686008$

Price, M., Tone, E. B., \& Anderson, P. L. (2011). Vigilant and avoidance attention biases as predictors of response to cognitive behavioral therapy for social phobia. Depression and Anxiety, 28, 349-353. DOI: DOI: 10.1002/da.20791

Rao, P. A., Beidel, D. C., Turner, S. M., Ammerman, R. T., Crosby, L. E., \& Sallee, F. R. (2007). 
Social anxiety disorder in childhood and adolescence: Descriptive psychopathology. Behaviour Research and Therapy, 45(6), 1181-1191. doi:10.1016/j.brat.2006.07.015

Rapee, R. M., \& Heimberg, R. G. (1997). A cognitive-behavioral model of anxiety in social phobia. Behaviour Research and Therapy, 35(8), 741-756. doi:10.1016/S00057967(97)00022-3

Rytwinski, N. K., Fresco, D. M., Heimberg, R. G., Coles, M. E., Liebowitz, M. R., Cissell, S., \& ... Hofmann, S. G. (2009). Screening for social anxiety disorder with the self-report version of the Liebowitz Social Anxiety Scale. Depression and Anxiety, 26(1), 34-38. doi:10.1002/da.20503

Schmidt, N., Richey, J., Buckner, J., \& Timpano, K. (2009). Attention Training for Generalized Social Anxiety Disorder. Journal of Abnormal Psychology, 118, 5-14. DOI: 10.1037/a0013643

Silverman, W. K., Kurtines, W. M., Ginsburg, G.S., Weems, C. F., Rabian, B., Serafini, L. T. (1999). Contingency management, self-control, and education support in the treatment of childhood phobic disorders: a randomized clinical trial. Journal of Consulting and Clinical Psychology, 67(5), 675-687. DOI: 10.1037/0022-006X.67.5.675

Spector, I. P., Pecknold, J. C., \& Libman, E. (2003). Selective attentional bias related to the noticeability aspect of anxiety symptoms in generalized social phobia. Journal of Anxiety Disorders, 17, 517-531. DOI: 10.1016/S0887-6185(02)00232-3

Sposari, J. A., \& Rapee, R. M. (2007). Attentional bias toward facial stimuli under conditions of social threat in socially phobic and nonclinical participants. Cognitive Therapy and Research, 31, 23-37. DOI: 10.1007/s10608-006-9073-2 
Stein, M., Torgrud, L., \& Walker, J. (2000). Social phobia symptoms, subtypes, and severity: Findings from a community survey. Archives of General Psychiatry, 57, 1046-1052. DOI: 10.1001/archpsyc.57.11.1046.

Stroop, J. R. (1935). Studies of interference in serial verbal reactions. Journal of Experimental Psychology, 18(6), 643-662. DOI: 10.1037/h0054651

Turner, S. M., Beidel, D. C., \& Dancu, C. V. (1996). Social Phobia and Anxiety Inventory: Manual. Toronto, Ontario: Multi-Health Systems Inc.

Turner, S. M., Beidel, D. C., Dancu, C. V., \& Stanley, M. A. (1989). An empirically derived inventory to measure social fears and anxiety: The Social Phobia and Anxiety Inventory. Psychological Assessment, 1, 35-40. DOI: 10.1037/1040-3590.1.1.35

Turner, S. M., Beidel, D. C., Cooley, M. R., \& Woody, S. R. (1994). A multicomponent behavioral treatment for social phobia: Social effectiveness therapy. Behaviour Research and Therapy, 32(4), 381-390. doi:10.1016/0005-7967(94)90001-9

Van Bruekelen, G. J. P. (2006). ANCOVA versus change from baseline: More power in randomized studies, more bias in nonrandomized studies. Journal of Clinical Epidemiology, 59(12), 920-925. DOI: 10.1016/j.jclinepi.2006.02.007

Weiss, D. D., \& Last, C. G. (2001). Developmental variations in the prevalence and manifestation of anxiety disorders. In M. W. Vasey \& M. R. Dadds (Eds.), The developmental psychopathology of anxiety (pp. 27-43). New York.

Williams, J. M. G., Watts, F. N., MacLeod, C., \& Mathews, A. (1997). Cognitive psychology and emotional disorders. London: Wiley. 